\title{
'You Are Too Out!': A Mixed Methods Study of the Ways in Which Digital Divides Articulate Status and Power in China
}

\section{ZhiMin Xiao}

Address: Graduate School of Education, University of Exeter, Exeter, EX1 2LU, UK

Email: z.m.xiao@exeter.ac.uk

\begin{abstract}
This study investigates the differences in adolescent engagement with Information and Communication Technologies (ICT), such as computers, the Internet, and mobile phones. Involving 698 second-year high school students from urban, rural, and ethnic Tibetan regions of China, it finds that patterns of access and use indicate status and power, and the meanings teenagers pour into the technologies articulate social and educational differences. On average, Tibetans are disadvantaged in access, and the return on parental education is greater for the mainstream Han than it is for Tibetans. However, state 'preferential policies' have mitigated Tibetans' plight in use, which makes the least privileged Han students with parents having no more than six years of education.
\end{abstract}

Keywords: China; Digital Divide; High School; ICT; Tibet

\section{The Digital Divide as a Moving Target}

The term 'digital divide' was initially coined to describe the gap in access to computers and the Internet along factors such as age, gender, race, income, and education (NTIA, 1999: xiii). It drew much attention when the Internet began to penetrate into American society in the late 1990s (Gorski, 2005; Mossberger et al., 2003; Servon, 2002; van Dijk, 2006). As ICT 
become increasingly widespread, the gap in terms of access, or 'first-level' digital divide, is narrowing (Hargittai and Hinnant, 2008; Livingstone and Helsper, 2007; Peter and Valkenburg, 2006). Unsurprisingly, as Notten and colleagues point out, some people believe the so-called digital divide will disappear sooner or later as electronic devices and access to networks become cheaper and cheaper (2009), or in Pippa Norris's words to describe those cyber-optimists, 'the digital divide will eventually succumb to the combined forces of technological innovations, markets, and the state' (2001: 11). However, others, such as van Dijk (2005) and Warschauer (2003), contend that inequality in the Internet era is much more than a singular issue of access. As Gunkel notes, the disparity in the digital world, like technology itself, is actually 'a moving target' (2003: 504). It means that people first differ considerably in access then in how they use ICT for what purposes and that the differentiation in use often correlates significantly with user socio-demographic profiles.

Indeed, although ICT are widely associated with new opportunities, development, and empowerment (Benkler, 2006), they are also found to have exacerbated existing inequalities in society, as those on the wrong side of the inequality lose out on various opportunities through the 'second level' divide in use (Bonfadelli, 2002; DiMaggio et al., 2004; Eynon and Geniets, 2016; Hargittai, 2010; Hargittai and Litt, 2011; Livingstone and Helsper, 2007; Qiu, 2009; Warschauer, 2011; Wilkin et al., 2017). In education for instance, students from more privileged social groups are more likely to have better connections at home, more access points, and do more 'capital-enhancing' activities (Micheli, 2015) online than do those from less privileged backgrounds, who are more likely to use technologies less frequently and for fewer activities (Hargittai and Hinnant, 2008; Livingstone and Helsper, 2007). Even when a few studies find those less socially privileged spending more time online, as Warschauer (2011) mentions, they report them using ICT more often for entertainment like playing computer games, chatting via text messages, or downloading music (see also Jackson et al., 
2008: 441).

Simply put, the more are having more and the socially advantaged are reaping more benefits from using ICT than are those already disadvantaged in society and education (Livingstone and Helsper, 2007; Norris, 2001; van Dijk, 2005). The digital divide may have narrowed in terms of access, but the differentiation in use is largely mirroring or even exacerbating existing social and educational inequalities, and it is reasonable to predict that the consequence of use will differ along similar lines of user characteristics.

Despite the research findings summarised above, it is not difficult to find optimistic generalisations about young people and new technologies. Young people growing up surrounded by ICT are often called 'Digital Natives' (Prensky, 2001) or 'Net Generation' (Oblinger and Oblinger, 2005; Tapscott, 1998). Through their engagement with ICT, the Net Generation, as Tapscott (2009) claims, are 'superimposing' their culture on the rest of the society, and becoming 'a force for social transformation.' They think, learn, work, and socialise, as people who accept the implications of those terms relate, in so profoundly different ways that there exists an emergent need for educators and parents, or 'Digital Immigrants' (Prensky, 2001), to rethink or even 'overhaul' conventional ways of raising, educating, and interacting with today's youths.

The generalisations above have enjoyed much popularity, as they represent a reassuring story technology enthusiasts want to tell and the public want to hear (Turkle, 2011). However, the heroic discourse does not tell a full story. We may call some of the teenagers digital natives in terms of the core operational skills they have to exhibit (van Deursen and van Dijk, 2011, 2014), but their lived experiences in cyberspace vary considerably, and the effectiveness in use is shaped to a great extent by their socio-demographic profiles. Therefore, any uncritical approach to the relation between young people and ICT represents an 'ahistorical' way to 
speculate what will happen and ignores the fate of some previous and present technologies in society (Selwyn, 2011).

\section{Technological Determinism}

According to Gunkel (2003), the digital divide is a big concern partly because those who are concerned have embraced in their discourses at least some elements of technological determinism, which views technology as the 'prime mover' in history and the 'sole cause' of change in society (Chandler, 1995: 2). Although many people do not harbour such a 'hard' deterministic view about the relationship between technology and society, a significant number do adopt a 'soft' deterministic view and regard technology as 'a key factor that may facilitate change' (Gunkel, 2003: 510, original italics).

When employed to analyse inequality in the Internet era, technologically deterministic views can intensify the concerns adults have about ICT's sure effects on children and young people, be they haves or have-nots. For the haves, technologies are changing not only how they learn, socialise, and live their lives (Tapscott, 2009), but also their bodies, for instance, brain structure (Carr, 2010). For the have-nots, missing out online means losing socioeconomic opportunities and life chances offline (van Dijk, 2005). Unsurprisingly, the way the term denotes inequality has justified its wide adoption, for the seemingly technological phenomenon has significant social and educational ramifications.

\section{Sociocultural Determinism}

While focusing on what ICT have done or can do to people and society, one risks ignoring the multiple ways people and society shape how new technologies are approached and used. In contrast to technological determinism, sociocultural determinism 'presents technologies and media as entirely subordinate to their development and use in particular socio-political, 
historical, and culturally specific contexts' (Chandler, cited in Gunkel, 2003: 512). When studying the digital divide, people subscribing to this view would argue that who you are and where you come from can explain how you interact with ICT and for what purposes.

Research has found that socioeconomic status is a reliable predictor of how students incorporate the Internet into their daily lives, for instance, more socially privileged students use the Web 'in more informed ways for a larger number of activities' (Hargittai, 2010; Hargittai and Hinnant, 2008), they seek health information and study online courses, instead of gambling and playing computer games, which often correlate negatively with academic performances (see also Jackson et al., 2008).

Similar findings have been reported in research conducted outside the US. For example, using data from 30 nations, Valkenburg and colleagues (2009) found that mid-adolescents from higher social status and two-parent families were more likely to have home access to ICT and use the Internet for informational purposes than were those from lower status segments. Moreover, 15 year olds in their study from single-parent families were not only less likely to have home access to networked computers, but also more likely to use the Internet for computer games, communication, as well as information. Even more striking in the study is the negative correlation found between a country's GDP level and its youths' use of ICT for entertainment.

Given the fast-changing nature of ICT, the above study conducted in 2003 (though published in 2009) may be too outdated. However, when the team surveyed 749 Dutch teenagers between 13 and 18 years old in 2005 to test whether the digital divide was disappearing or emerging, they found similar patterns even in one of the world's most connected countries the Netherlands (Peter and Valkenburg, 2006).

When users of the Internet from wider age groups are studied, sociocultural determinants 
become even more relevant. More recently, using representative survey data from thousands of respondents, a team in Switzerland studied the social differences of Internet use in five developed countries with the highest level of Internet penetration, they found that sociodemographics alone explained up to half of the variance in usage (Büchi et al., 2016). By and large, the digital divide examined under sociocultural determinism is a symptom rather than a cause of socioeconomic inequality (Gunkel, 2003).

\section{Volunteerism}

Nevertheless, the two extreme theories underestimate the roles individuals have to play in making technologies their own or keeping a distance from ICT. Users of ICT are not merely passive recipients of what is available. Instead, they evaluate, adopt, adapt, and integrate technologies into their daily lives - a process Miller (2013) called 'localization' - so that a chosen artefact becomes 'specific to the cultural concerns' of a region, serves individual purposes, and helps its users achieve their potentials. Chandler (1995) calls the voluntary elements that affect access and use 'volunteerism,' suggesting that individuals should have control over whether or not to use ICT.

As Gunkel argues, while most digital divide studies 'employ forms of technological determinism in constructing their hypotheses and conclusions, they often support the theory of sociocultural determinism in the course of their investigations' (2003: 512), indicating that they usually approach the issue under scrutiny with two extreme stances regarding technology and society. Volunteerism, nevertheless, skilfully moves between the two and emphasises individual agency by insisting that active users of ICT such as students are not 'helpless automatons' (Chandler, 1995: 19) that are subordinate to either sociocultural or technological determinants.

As such, volunteerist scholars of the digital divide would question the widely-held 
assumption that individuals who decide not to participate in the digital era are necessarily 'falling into existing and deep-rooted patterns of social and economic inequalities' (Selwyn, 2006: 273). Surveying 100 respondents with an average age of 51.6 years old in England and Wales, Selwyn concludes that participants' non-use of ICT is mediated by 'conscious decisions and whims, on-going "life-flow" and deliberate changes in life circumstances' (2006: 289). In other words, non-users of ICT can exercise varying degrees of agency over their own engagement with technology, and non-participation is not necessarily associated with pejorative meanings.

\section{An Assessment of the Three Theories}

However, Selwyn does acknowledge that 'the opportunities to access and use computers are undeniably structured and mediated by factors relating to the household, family, workplace as well as age, class and gender' (2006: 289). This implies that one can hardly escape sociocultural influences when making decisions over whether or not to use ICT, and if so, how and how much. As such, when investigating (non-)participation in the digital world, one needs to view (non-)users as individuals with different informational needs rather than simply 'end users' of 'ready-made' technologies (Selwyn, 2006: 275). By so doing, the social process under which ICT are embraced or distanced will come under light and a better understanding of the digital divide is more likely to occur than otherwise.

Focusing on the social process is perhaps even more important in the case of youths' engagement with ICT than anywhere else, for teenagers' daily lives are subject to constant control or monitoring from adults. As Buckingham contends, today's youths 'are being aggressively targeted as consumers: their experiences of new media are framed and defined by broader social and economic forces that they do not control, or even necessarily understand' (2005: 26). Employing volunteerism to investigate young people and new media 
is valid to a certain extent, particularly in Western democracies where John Stuart Mill's concepts of liberty and individuality are held dear (1991: 78-82). However, volunteerism is unable to answer why new media have bigger and longer effects on some children and young people while smaller and shorter ones on others.

Note that the informants in Selwyn's study were mainly adults in their 50s, and in many ways, they had control over their lives, for instance, they chose to leave home computers to other family members such as children and husband (2006: 284). However, one can argue that even a mother's decision to let her husband and children interact with ICT is subordinate to her role as a wife and mother. Therefore, volunteerism alone is inadequate to help researchers of technology and society fully understand the inequality in question, particularly when it comes to the issue of young people and new media where social shaping of technology (non-)use is by far more noticeable than elsewhere. That being the case, it is not unwise to argue that adolescents' level and nature of engagement with ICT are socio-culturally shaped and in turn shaping their socioeconomic opportunities and life chances.

Taken separately to examine the digital divide, none of the three theories discussed is adequate enough to portray a full picture of the issue under concern. Taken together, they are more likely to yield sophisticated and progressive understandings of inequality in the Internet age. However, this does not mean that they are equally capable of reflecting or constructing social reality. Regarding adolescents' interaction with ICT, sociocultural determinism, as demonstrated in research cited earlier, has proven more effective a tool than the other two to study young people and new media and the inequalities associated with the phenomenon, just as Peter and Valkenburg maintain: 'If gaps close at one stage, they open at another' (2006: 297), and the characteristics of ICT users play a greater role than do the characteristics of technology in shaping its adoption, use, and impact among teenagers. In other words, 
sociocultural determinants have a stronger overall bearing than do the other two frameworks on students' level and nature of engagement with ICT.

Informed by the three theories regarding technology and society, this study aims to document the differences in adolescents' engagement with ICT in China by examining both qualitative and quantitative data collected from three different high schools.

\section{Deep Roots of Social Inequalities in Contemporary China}

To study the social structures within which digital inequalities situate, it is necessary to understand the major transformations that have sculptured what China is like today. According to Whyte (2010), China has undergone two major social transformations since 1949. The first was socialist in nature and was launched by Mao and his colleagues during the 1950s. The second started in 1978 and embraced capitalist market into the socialist state. Regarding the consequences of the two transformations, conventional discourse goes like this: the first aimed to eradicate the gigantic social gaps of the 'feudal' society, and it was made possible largely 'through class struggle and the creation of socialist institutions in the mid-1950s' (Whyte, 2010), regardless of the impacts those changes would have on the country's economic growth; the second emphasised economic development over everything else, and it was achieved mainly through the encouragement of foreign direct investment, introduction of market competition, and promotion of export, regardless of the effects those measures would have on social inequality. By the first decade of the $21^{\text {st }}$ century, China has become once again very unequal (Ming, 2009; Whyte, 2010; Xiang, 2007), which is reflected in the differences in adolescent access to and use of ICT (Wallis, 2011). That is to say, the 'divides' we observe today right in front of our eyes are historically deep.

Having traced how socioeconomic history shapes inequality in China, it is time to examine the roles ethnicity plays in the digital divide. Also in the 1950s, the Chinese state identified 
56 ethnic groups according to their unique cultural and linguistic marks that had been persistent over time (Cheng, 2010), and designed a series of policies aiming to help minority regions to develop (Postiglione, 2008). Those social arrangements are called 'preferential or ethnic policies,' which confer a long list of benefits that only officially recognised groups, including the Tibetans in this study, are entitled to (Cheng, 2010; Sautman, 1999), and the benefits usually cover education, housing, and family planning (Hu and Salazar, 2010).

\section{Aims, Methods, and Contexts}

As part of a broader study (Xiao, 2013), the research described here examined the ways in which social and educational factors related to technology access and use and the meanings and values students poured into the technologies under concern. At the operational level, the study set out to answer the following research questions. How do variables such as students' socioeconomic status (approximated by parental education in years), ethnicity (Tibetan vs. Han), and locale (urban vs. rural) relate to their level (e.g., personal, home, and school access to ICT) and nature (e.g., what do they do with technology) of interactions with ICT? What do ICT mean to students of different sociodemographic profiles, and how do they engage with them, given different constraints they face?

Due to the nature of the research questions raised above, neither quantitative nor qualitative methods alone can make a satisfying picture of students' digital lives across such geographically, culturally, and socioeconomically diverse groups of students (see also Robinson et al., 2015). If a small number of students are investigated qualitatively, the ability to generalise their perspectives to other students is weak and it is difficult to minimise biases (see Xiao et al., 2016 for why it is difficult, if not impossible, to eliminate biases, even in randomised controlled trials) in data collection, analysis, and interpretation, despite its capability to illuminate or illustrate certain mechanisms or reasons behind some resultant 
survey findings (Creswell and Plano Clark, 2007; Plano Clark and Creswell, 2015). But if I only examine students in a great number by means of a survey, the ability to generate indepth understanding of individuals is diminished, despite its capability to uncover trends and relationships, and to keep a relatively safe distance between I as a researcher and the students as the researched. That's to say, the mixed methods employed in the study do not simply record behaviours, but they also treat students as people with purposes, feelings, and thoughts that animate who they are as individuals.

The study took place in three schools, namely, Nanshan in urban Shenzhen, Hengshan in rural Hunan, and Basum in the Tibet Autonomous Region (TAR) of China. Shenzhen is one of the most developed cities in China and it is often viewed as China's Silicon Valley. It is next to Hong Kong in Southern China. Hunan is an inland province in the central south, where the vast majority of its rural population are migrant workers in cities like Shenzehn. Unsurprisingly, most students in Hengshan are 'left-behind' (Xiang, 2007) children of migrant workers, which means many students there grow up with grandparents or other close relatives from very early on in childhood and rarely live with their parents for long. Basum is about three hours' coach ride away from the capital city of Lhasa in Tibet. Unlike those in Nanshan and Hengshan, Basum students are from across the TAR in the north-west, not just nearby counties of Basum. Consequently, the students are much more diverse in terms of socioeconomic profile than their counterparts are in the other two schools. Nonetheless, all Basum students surveyed in the study are Tibetan.

Students in the three schools were recruited through presentations about the study made to all chosen classes in year 2 of each school, which means they are are of similar age (17.4 years old on average). Classes in each school were carefully selected so as to represent Arts and Science, Key and Ordinary tracks. In the presentation, students were verbally assured of 
confidentiality. Prior to their completion of a paper-and-pencil survey, they were asked to read a brief description of the study and sign to proceed. It was also made clear to all students that they could choose not to participate and were free to withdraw from the study at any time. It is worth noting that the pen-and-pencil survey, like the one utilised in Hargittai and Litt (2011) about twitter adoption in America, is vital in the study because it helps avoid bias against those who are less likely to use or familiar with ICT, let alone the fact that the study's primary focus is on differentiated access and use.

The three schools are purposive samples in the study, which means they are particular settings that are 'deliberately selected for the important information they can provide that cannot be gotten as well from other choices' (Maxwell, 1997). This strategy responds to the objectives of the qualitative strand of the study so that new insights or fresh aspects regarding ICT appropriation in China can be solicited. Unlike probability sampling, purposive samples aim to increase the transferability of the study, suggesting each school represents a broader group of schools as closely as possible and the selection of the three schools allows for comparability between the three types of schools on key dimensions of students' relations with ICT (Teddlie and Yu, 2007).

Interviewees were selected from respondents who agreed to be interviewed and left their contact details in the pen-and-pencil survey. All students in the chosen classes of each school completed the survey, and in total, there were 698 survey respondents. However, more students expressed willingness to be interviewed than I needed in the study. I had to make decisions on which students I should choose for the following-up in-depth interviewing. My principle was to include students with different levels of access to ICT, family backgrounds, academic performances, track (Arts vs. Science), and attainment status (Key vs. Ordinary classes). This strategy is what Collins (2010) calls 'stratified purposeful sampling.' It is 
stratified because the sampling boundary is divided into subgroups where members are relatively homogeneous with respect to the above-mentioned characteristics. However, it also embraces the principle of 'maximum variation' (Collins, 2010), meaning a variety of groups were selected so that I could maximise the range of perspectives about ICT in the study or enhance 'informational representativeness' (Sandelowski, 2000). In the end, 45 students were interviewed, with 15 from each school.

The vast majority of the students studied in the project live in school dormitories and strive for one goal, which is to pass the National College Entrance Exam, known as Gaokao in China. The exam is held once every year throughout the country. An overall score one achieves in the Gaokao has significant consequences for life chances, and for many, it has life-transforming effects. Since competition for university places is fierce, one mark can sometimes make a considerable difference. The entry requirement varies from university to university, and even within one university, different grades are often required of applicants for different majors. Universities also set different quotas for different areas where they are allowed to recruit students. As a result, students in less economically developed areas often need to study differently, if not harder, in order to get into universities in places where there are more higher education institutions, which are often more developed cities like Beijing, Shanghai, or Guangzhou.

The Gaokao has different meanings to students of different sociodemographic profiles. To those on the international track in Nanshan, it is irrelevant, as they prepare for foreign exams to study abroad. They do not face the constraints their counterparts on the Gaokao track have to negotiate in order to interact with ICT. To most others in the study, the Gaokao affects how they engage or refuse to engage with their studies and ICT. To put it differently, they must behave in pragmatic and strategic ways in order to satisfy the 'consequential validity' 
(Selwyn, 2011: 109) of the high stakes Gaokao.

\section{Findings}

\section{School Hengshan in Hunan}

All schools in the study banned students' visit to Internet cafés (known as wangba in Chinese), but the negotiations between adults and students in Hengshan are among the most dramatic. Hengshan students were so 'addicted' to wangba that they sometimes jumped from the first floor of monitored dormitory to the ground floor in order to escape surveillance cameras. Once in wangba, they were pleased even when all machines were occupied and what they could do was often left to watching others interacting with those slow yet seductive computers, as Xin recalled his own experience:

It's only occasionally that I myself get a chance to lay my own hands on a machine, cos there are too many people there whenever I have time to pay a visit. Rarely are there machines available after $1 \mathrm{PM}$ - post-lunch time. There are so many people there that I can only watch. But I'd occupy one as soon as one becomes available.

Guoyu has no access to a computer at home. As many of his classmates do, he usually visits wangba on weekends during term time. Like many others in Hengshan, it is in wangba that he learns most of the operational skills associated with computers and the Internet.

I didn't even know how to switch on or off a computer...now it's okay. I am just slow in typing...it's because people communicate differently while typing, which I sometimes find hard to understand. Some use numbers to represent words, for instance, two 8s mean 'bye-bye.' The other day, somebody sent ' 88 ' 
to me. I kept asking what he meant. He replied: 'You are too out!' Cos I didn't know the meaning.

Some students visit wangba to satisfy informational needs. Ting once went there with her friend to search for information about degrees for higher education, entry requirements of different universities, and possible career options different choices she was going to make might imply.

Others were attracted to wangba because, according to Xin and Guoyu, they were bored or lonely in school. When this is the reason, Chan was right to argue: 'For them [addicts], addiction is not a state to be diagnosed but is itself diagnostic; addiction leads them to social criticism' (2008: 130). That is to say, had the students' social and informational needs been met, they might have behaved differently.

\section{School Basum in Tibet}

Basum students have an even lower level of access to ICT than those in Hengshan do (see Figure 1 a). Those with home access in the TAR are likely to have at least one parent working for the state and they usually started using computers earlier. The digitally disadvantaged tend to come from agricultural or nomadic Tibet. Nonetheless, there are over a dozen of wangba in the town where Basum is. Most students go there during vacations; and as soon as weekends approach, wangba become full. Unsurprisingly, wangba are primary places for Basum students to hang out, even for those with a home computer.

Zaxipubu and Bianjiucilie were interviewed at the same time. The two students come from different socioeconomic backgrounds. Zaxipubu's parents are working for state units and he has used eight mobile handsets. Bianjiucilie comes from nomadic Tibet. Unlike Zaxipubu, he is shy and less fluent in Mandarin. When probed with questions, the former often offered his understanding of his friend's circumstances, and the latter usually nodded with an infectious 
smile on his face. Despite the difference in socioeconomic profiles, the two students have many shared experiences with ICT. For instance, they visit wangba almost every weekend, and spend whole nights there often. Like many others in wangba, they play games, chat online, and watch films. However, Zaxipubu considers Bianjiucilie 'addicted' to computer games, for, in his view, Bianjiucilie often forgets to eat while in wangba; and in school, he is many a time low in spirit. Sitting besides Zaxipubu, Bianjiucilie did not disagree. Instead, he disclosed how much he spent per month.

Since students of agricultural and nomadic backgrounds in Tibet are not required to pay tuition fees, and every month they receive from the state around 180 Yuan as a stipend, Bianjiucilie has enough pocket money at his disposal when his parents and uncle give him extra 500 Yuan per month. With both parents working in state units, Zaxipubu is not entitled to the benefits. However, he stressed that 500 Yuan is easy to expend in Tibet nowadays, and he highlighted: 'We can't cope without wangba in school. We go there whenever we feel bored on weekends.'

While wangba function as public places for students like Bianjiucilie to play games, they also provide opportunities for teenagers such as Dunzhulaba to develop interests in music and to learn English. With a home computer, Dunzhulaba still frequents wangba, for the speed there is much faster than his home's.

Mobile phones are of great significance to Basum students too, although they are less likely to own one than their counterparts are in Hengshan and Nanshan. When they do have one, they are more likely to use a less well-known brand. Interviewees Yuzhengesang and Qupeisuolang are cousins. The former's father is a Deputy Head of Basum, and the latter comes from rural Tibet. Yuzhengesang has at home a computer and several mobile phones. When Qupeisuolang saw a few of his cousin's handsets, he wanted one, as Yuzhengesang 
commented: 'Every time he asked me for a phone. After I told him that he would have lost it if I gave him one, he was upset. He keeps asking me for a [used] phone!' The handset Cirenbianba has is a brand called Hualu, with which most users in inland provinces are probably unfamiliar. 'Some students don't have a phone probably because their family can't afford one.' He said: 'Others bring real Nokia handsets to school. I am going to buy a Nokia 85 tomorrow.'

\section{School Nanshan in Shenzhen}

The views towards those without a phone in Nanshan can be poignant and the have-nots are sometimes excluded from 'the flow of social events' (Ling, 2012). For instance, Yanhai once chose not to use her mobile phone on campus, and her roommates called her 'Miss Extinction' (miejue shitai), implying she is rare to find, bad-tempered, and difficult to get along with these days. If anyone does not have a mobile phone, Yanzi would think they are 'not in the same world.' She would keep a certain distance from those who do not have or just refuse to use a phone, no matter how good they are in other aspects. She considers them 'a little eccentric' (youdian yilei).

Pin, however, associates have-nots with socioeconomic disadvantage. He grew up in Chongqing, a Southwestern metropolis, and transferred to Nanshan a few years ago. In his view, Shenzhen residents should be relatively richer than those in Chongqing. When he sees someone in his school without a phone, he is first surprised and then wonders why. He also considers stark the social inequality in Shenzhen:

There exists among us a mentality to catch up with others in material wealth. Even in our class, although we all wear the same uniform, you can see the differences in the bags your classmates carry, the meals they take in the school dining hall, and the pens they use - some students can (afford to) throw one 
away without hesitation when it ceases to function well; but it would take others a long time to make such a decision.

In cyberspace, Nanshan students also exhibit considerable variation in accruing the digital capital (Ignatow and Robinson, 2017; van Deursen and van Dijk, 2015). For instance, Qingpeng is a student of the school's international class, where students prepare for overseas exams and aim for higher education abroad. This class has its own teachers and follows its own curricula. Students of the class are free to bring with them their mobile phones and laptops. As Qingpeng commented, all his classmates have gadgets like iTouch, iPhone, etc. Unlike the ordinary track for the National College Entrance Examination, the international track has its own classrooms where students can charge their ICT, notwithstanding that they all live on the same campus and share the same library and dining hall. Clearly, technology is not a great equaliser in Nanshan.

The contrast manifests also in how students use ICT. For instance, Qingpeng often visits Wikipedia, follows Open Yale Courses, and searches for information about universities and colleges in the US and UK. He also knows the endowment sizes of many American liberal arts colleges and those of some British universities. He compares the information before making decisions on where to apply. He even knows certain rules about doing a $\mathrm{PhD}$ and making grant applications in America and England. In Shenzhen and other cities of China, there are many students like Qingpeng today, they either entirely follow foreign curricula and ways of learning, or combine the best of Chinese and Western systems. Meanwhile, their counterparts in schools like Hengshan and Basum or even the same school of Nanshan are facing very different life trajectories, and such differences often translate into the ways students appropriate and interact with ICT.

Since most Nanshan students own a home computer, they have the most to say about it. To 
Sin, a computer connected to the Internet opens a whole new world for him. 'Without access to the Internet for a month,' said he, 'you would know nothing about the world.' Sin relies heavily upon the Internet for information about the world and the country. He praised the roles the Internet has to play in government transparency and his own understanding of political corruption:

Corruption to me is all too normal. 'Upright officials' are not those who were never corrupt, but those who have accomplished a lot for the people. One classic comment I would like to borrow from the Internet is: 'Corruption, who cares! But you must do something for the people.' Upstanding officers, meaning executives who are not unprincipled, now refer to those who are genuinely concerned about what they can do for the people, not those who only concern themselves with what they can get from the people.

While many students in Hengshan and Basum are still learning how to type, Sin is utilising the Internet to expand and perhaps challenge his understanding of the world. This is what Norris (2001) called a 'democratic divide' — users of ICT are divided in how and how much they seek political knowledge.

\section{A Synthesis}

As narrated above and illustrated in Figure 1, adolescent access to and use of ICT are not random, and they significantly correlate with where they are (which school), who they are (family background as measured by parental education), and where they stand in school (Arts versus Science and Key versus Ordinary). To be more specific, Nanshan students have the highest level of access to ICT and support (see Figure 1 a and c), use technology for the widest range of purposes (Figure $1 \mathrm{~b}$ ), and are most likely to treat ICT as 'thought' companions for social and intellectual gains (Ignatow and Robinson, 2017; van Deursen and 
van Dijk, 2015). But in Hengshan and Basum, many teenagers of a similar age are still familiarising themselves with keyboard skills in wangba, which Nanshan students are least likely to visit but most likely to disdain, as reflected in the following view of a student interviewed in Nanshan:

It has been internalised since we were little. It's like your first reaction to cockroaches; you don't need to experience it [before you know how disgusting it is]. It is intuitive. We were taught not to visit wangba when we were primary school students...today everybody has a computer at home. There is no need [for us] to go there. Those who frequent wangba probably don't have home access to a computer, and I feel, like, some who go there are, either not welleducated or their parents are too strict to tolerate their use [of a computer] at home.

Regarding ethnicity and the differences in access and use, one dominant theme is that Tibetan students are disadvantaged relative to the mainstream Han in overall access to ICT and total number of activities with ICT. However, rural Han students in Hunan are also disadvantaged in those aspects relative to their urban counterparts in Shenzhen. The digital marginalisation as identified above is thus not entirely due to ethnicity. If we compare the outcomes between Basum and Hengshan, we can find that Tibetan teenagers had a much lower level of overall access (Figure $1 \mathrm{a}$ ), but the two groups did not differ considerably in the number of total activities with ICT (Figure $1 \mathrm{~b}$ ). This finding is due in part to the popularity of wangba as an important means for shared access in Tibet. It also has something to do with the aforementioned preferential policies, such as lower scores required of Tibetans for higher education, which are reflected in the number of weekends students had - Basum teenagers had one weekend off almost every week, whereas those in Hengshan had two days off every two weeks, meaning less time for technology. 
If we use ethnicity, parental education, and the interaction of the two variables, three terms that remain to be statistically significant in covariate selection, to account for the variation in the total number of activities students do with the Internet, we can see more aspects of the inequality under concern. As reported in Table 1, all terms but one are significantly correlated with the outcome variable. The intercept is 2.20 , which is the expected number of Internet activities for Han students whose parents have no formal education. Relative to Han students, Tibetans with parents having a similar educational background actually use the Internet for almost one more activity on average. However, as parental education increases, Tibetans begin to lag behind, for the strength of correlation between the outcome and being Han, as indicated by the slope of the solid line in Figure 2, is much bigger than that between the outcome and being Tibetan, which is represented by the slope of the dashed line. Figure 2 also shows the vertical distance between the two regression lines across all levels of parental education is not constant. It first decreases until around six years of parental education, then increases as parental education increases. This change implies being Han has a stronger correlation with the outcome at either end of parental education, whereas the magnitude of correlation between the outcome and being Tibetan is relatively stable.

Also reported in Table 1, the expected difference in outcome between two mainstream Han students with one year difference in parental education is 0.22 ; but for Tibetans, the average difference is only 0.03 , suggesting the return on parental education is by far smaller for Tibetans than it is for the Han (see also Figure $1 \mathrm{~d}$ ). This further reveals that, on average, Tibetans are disadvantaged, but the most disadvantaged are those Han students whose parents have no more than six years of education, leaving urban Han youths the most privileged in terms of activities with ICT. The above results are based on complete cases, but the patterns are almost consistent across all datasets with imputed missing values (Honaker et al., 2012), as shown in Table 2. 
To find more robust evidence for the conclusions made above, we can also simulate in Zelig (Imai et al., 2013) 1,000 first differences in outcome between Han and Tibetan students by holding constant all covariates at their means in each of the ten datasets that differ only in imputed missing values. The mean difference, together with its $95 \%$ confidence interval produced in $R$, is $0.85[0.33,1.37]$, suggesting Han students engage with the Internet for 0.85 more purposes than their Tibetan counterparts do on average, given they all come from similar socioeconomic backgrounds. But when we controlled for ethnicity and compared the differences in outcome within Han and Tibetan students who differ only in parental education, i.e. 0 versus 18 for Han and 0 versus 16 for Tibetan students (observed minimum and maximum values for parental education within the two groups). The simulated first differences and their $95 \%$ confidence intervals are $0.57[-0.92,2.06]$ and $3.90[2.87,4.95]$ for Tibetan and Han students respectively, suggesting the divide within the mainstream Han is over six times bigger than that within the Tibetans, and over four times bigger than the ethnic divide.

\section{Conclusion}

Students' interactions with ICT bespeak their specific geopolitical, ethnocultural, and socioeconomic positions in China. Geographically, the high plateau in Tibet shapes how and how often students visit home and places outside the town where Basum is. Since students in Basum come from across the TAR, the school and the town are their home away from home - unlike students in Nanshan and Hengshan, they cannot visit home until a long vacation arrives. Politically, education is sometimes treated as a 'task' in Tibet, which affects how students learn and teachers teach. For instance, students enjoy more free weekends, a monthly stipend, and need lower entrance requirements for higher education than their counterparts in the other two schools do. All these relate to the patterns of access and use. 
Socioeconomically, rural and nomadic teenagers in Basum are most constrained in their access to mobile phones - they often have no access at all or use lower-end poorer-quality mobile handsets. Nevertheless, state preferential policies have mitigated their plight to a certain degree. This leaves mainstream Han students with parents having no more than six years of education most disadvantaged. However, the ethnic gap is likely to persist if the return on parental education continues to privilege the mainstream Han.

The meanings teenagers encode in their ICT also articulate social and educational differences in China, which permeate youth interactions with the technologies. To some, the Internet is a window to the outside world and an imagined future when they utilise it to satisfy their informational needs and transfer access as one form of economic capital to educational opportunity as a cultural capital (Ignatow and Robinson, 2017; van Deursen and van Dijk, 2015). To others, cyberspace is an ideal place to socialise with like-minded people of a similar age. The values students pour into ICT are not always clear, as are the meanings in Strang's analysis of water (2006). However, they do surface when they 'swirl' in the powerful underflow of negotiation and control. Taken together, the patterns of access and use are indicative of status and power, and the meanings and values with which students invest ICT are embedded in the ways students have been raised and taught.

Nevertheless, it is important to note the following limitations. First, the outcomes in the quantitative strand of the research are measured as sums of access to computers, the Internet, and mobile phones in and out of schools and total numbers of activities students use the technologies for. They do not reflect the dynamic networks of student relationships with ICT and one another. While research on digital divide elsewhere (Micheli, 2015; van Deursen and van Dijk, 2014) has moved beyond access to focus on skills, this study still concerns the first level of access quantitatively. Although it is appropriate in China, as we can see in the 
findings, it is rather bland. Second, it does not frame the research under a western technology diffusion theory, such as the S-curve (see van Deursen and van Dijk, 2015). This is partly because the study does not look at just one piece of digital technology, such as the Internet. But it is also due to the fact that the diffusion theory lacks explanatory power in Tibet and that not all of the technologies considered will reach full saturation.

\section{Acknowledgements}

I gratefully acknowledge a generous Durham Doctoral Fellowship, without which the study would not have been possible. I am also thankful to Professor Steve Higgins of Durham University for his supervision of the research project.

\section{Disclosure Statement}

There is no financial interest or benefit to declare.

\section{References}

Benkler Y (2006) The Wealth of Networks: How Social Production Transforms Markets and Freedom. New Haven; London: Yale University Press.

Bonfadelli H (2002) The Internet and Knowledge Gaps: A Theoretical and Empirical Investigation. European Journal of Communication 17(1): 65-84. DOI: $10.1177 / 0267323102017001607$.

Büchi M, Just N and Latzer M (2016) Modeling the second-level digital divide: A fivecountry study of social differences in Internet use. New Media \& Society 18(11): 27032722. DOI: $10.1177 / 1461444815604154$.

Buckingham D (2005) Schooling the Digital Generation: Popular Culture, the New Media and the Future of Education. London: Institute of Education, University of London.

Carr NG (2010) The Shallows: How the Internet Is Changing the Way We Think, Read and Remember. London: Atlantic Books. 
Chan AS (2008) Slashdot.org. In: Turkle S (ed.) Inner History of Devices. Cambridge, Mass.; London: MIT Press, pp. 125-137.

Chandler D (1995) Technological or media determinism. Available at: http://www.aber.ac.uk/media/Documents/tecdet/tdet01.html (accessed 11 January 2013).

Cheng H (2010) Educational barriers for migrant children in China: A mixed-methods analysis focused on ethnic minorities. Columbia University, New York.

Collins K (2010) Advanced sampling designs in mixed research. In: Tashakkori A and Teddlie C (eds) Sage Handbook of Mixed Methods in Social \& Behavioral Research. London: Sage.

Creswell JW and Plano Clark VL (2007) Designing and Conducting Mixed Methods Research. London: SAGE Publications.

DiMaggio P, Hargittai E, Celeste C, et al. (2004) Digital inequality: From unequal access to differentiated use. Social Inequality. Russell Sage Foundation.

Eynon R and Geniets A (2016) The digital skills paradox: how do digitally excluded youth develop skills to use the internet? Learning, Media and Technology 41(3). Taylor \& Francis: 463-479. DOI: 10.1080/17439884.2014.1002845.

Gorski P (2005) Education equity and the digital divide. Association for the Advancement of Computing In Education Journal 13(1): 3-45.

Gunkel D (2003) Second thoughts: Toward a critique of the digital divide. New Media \& Society 5(4): 499-522. DOI: 10.1177/146144480354003.

Hargittai E (2010) Digital Na(t)ives? Variation in Internet Skills andUses among Members of the 'Net Generation'. Sociological Inquiry 80(1): 92-113. DOI: 10.1111/j.1475682X.2009.00317.x.

Hargittai E and Hinnant A (2008) Digital Inequality: Differences in Young Adults' Use of the Internet. Communication Research 35(5): 602-621. DOI: $10.1177 / 0093650208321782$.

Hargittai E and Litt E (2011) The tweet smell of celebrity success: Explaining variation in Twitter adoption among a diverse group of young adults. New Media \& Society 13(5): 824-842. DOI: 10.1177/1461444811405805.

Honaker J, King G and Blackwell M (2012) Amelia II: A Program for Missing Data. Available at: http://gking.harvard.edu/amelia.

Hu X and Salazar MA (2010) Ethnicity, Rurality, and Status: Hukou and the Institutional and Cultural Determinants of Social Status in Tibet. In: Whyte MK (ed.) One Country, Two Societies: Rural-Urban Inequality in Contemporary China. Cambridge, Mass.: Harvard University Press.

Ignatow $\mathrm{G}$ and Robinson L (2017) Pierre Bourdieu: theorizing the digital. Information Communication and Society 20(7). Taylor \& Francis: 950-966. DOI: 10.1080/1369118X.2017.1301519. 
Imai K, King G and Lau O (2013) Zelig: Everyone's Statistical Software. Available at: http://gking.harvard.edu/zelig.

Jackson LA, Zhao Y, Kolenic A, et al. (2008) Race, Gender, and Information Technology Use: The New Digital Divide. CyberPsychology \& Behavior 11(4): 437-442. DOI: 10.1089/cpb.2007.0157.

Ling RS (2012) Taken for Grantedness: The Embedding of Mobile Communication Into Society. Cambridge, Massachusetts; London, England: The MIT Press.

Livingstone S and Helsper E (2007) Gradations in digital inclusion: Children, young people and the digital divide. New Media \& Society 9(4): 671-696. DOI: $10.1177 / 1461444807080335$.

Maxwell JA (1997) Designing a qualitative study. In: Bickman L and Rog D (eds) Handbook of Applied Social Research Methods. London: Sage.

Micheli M (2015) What is New in the Digital Divide? Understanding Internet Use by Teenagers from Different Social Backgrounds. Communication and Information Technologies Annual 10: 55-87. DOI: 10.1108/S2050-206020150000010003.

Mill JS (1991) On Liberty and Other Essays. Oxford; New York: Oxford University Press.

Miller D (2013) Social Networking Sites. In: Horst HA and Miller D (eds) Digital Anthropology. London: Bloomsbury, pp. 146-164.

Ming HH (2009) Growing up in the urban shadow: Realities and dreams of migrant workers' children in Beijing and Shanghai. Cambridge, Mass.

Mossberger K, Tolbert CJ and Stansbury M (2003) Virtual Inequality: Beyond the Digital Divide. Washington, DC: Georgetown University Press.

Norris P (2001) Digital Divide: Civic Engagement, Information Poverty, and the Internet Worldwide. Cambridge: Cambridge University Press.

Notten N, Peter J, Kraaykamp G, et al. (2009) Research Note: Digital Divide Across Borders-A Cross-National Study of Adolescents' Use of Digital Technologies. European Sociological Review 25(5): 551-560. DOI: 10.1093/esr/jen071.

NTIA (1999) Falling Through the Net: Defining the Digital Divide. U.S. Department of Commerce.

Oblinger D and Oblinger JL (2005) Educating the Net Generation. Washington, DC: Educause.

Peter J and Valkenburg PM (2006) Adolescents' internet use: Testing the 'disappearing digital divide' versus the 'emerging digital differentiation' approach. Poetics 34: 293305. DOI: 10.1016/j.poetic.2006.05.005.

Plano Clark VL and Creswell JW (2015) Understanding Research: A Consumer's Guide. 2nd ed. London: Pearson Education. 
Postiglione GA (2008) Making Tibetans in China: the educational challenges of harmonious multiculturalism. Educational Review 60(1): 1-20. DOI: 10.1080/00131910701794481.

Prensky M (2001) Digital natives, digital immigrants Part 1. On the Horizon 9(5): 1-6. DOI: $10.1108 / 10748120110424816$.

Qiu L (2009) Working-Class Network Society: Communication Technology and the Information Have-Less in Urban China. Cambridge, Massachusetts; London, England: The MIT Press.

Robinson L, Cotten SR, Ono H, et al. (2015) Digital inequalities and why they matter. Information Communication and Society 18(5). Taylor \& Francis: 569-582. DOI: 10.1080/1369118X.2015.1012532.

Sandelowski M (2000) Combining qualitative and quantitative sampling, data collection, and analysis techniques in mixed-method studies. Research in Nursing \& Health 23: 246255. DOI: 10.1002/1098-240X(200006)23:3<246::AID-NUR9>3.0.CO;2-H.

Sautman B (1999) Expanding Access to Higher Education for China's National Minorities: Policies of Preferential Admissions. In: Postiglione GA (ed.) China's National Minority Education: Culture, Schooling, and Development. New York; London: Falmer Press.

Selwyn N (2006) Digital division or digital decision? A study of non-users and low-users of computers. Poetics 34(4--5): 273-292. DOI: 10.1016/j.poetic.2006.05.003.

Selwyn N (2011) Schools and Schooling in the Digital Age: A Critical Analysis. London: Routledge.

Servon LJ (2002) Bridging the Digital Divide: Technology, Community, and Public Policy. Oxford: Blackwell Publishing.

Strang V (2006) The Meaning of Water. Oxford: Berg.

Tapscott D (1998) Growing Up Digital: The Rise of the Net Generation. New York: McGraw-Hill.

Tapscott D (2009) Grown Up Digital: How the Net Generation Is Changing Your World. New York: McGraw-Hill.

Teddlie C and Yu F (2007) Mixed methods sampling: A typology with examples. Journal of Mixed Methods Research 1(1): 77-100. DOI: 10.1177/2345678906292430.

Turkle S (2011) Alone Together: Why We Expect More from Technology and Less from Each Other. New York: Basic Books.

Valkenburg PM and Peter J (2009) Social Consequences of the Internet for Adolescents: A Decade of Research. Current Directions in Psychological Science 18(1): 1-5. DOI: 10.1111/j.1467-8721.2009.01595.x.

van Deursen A and van Dijk J (2011) Internet skills and the digital divide. New Media \& Society 13(6): 893-911. DOI: 10.1177/1461444810386774. 
van Deursen A and van Dijk J (2014) The digital divide shifts to differences in usage. New Media \& Society 16(3): 507-526. DOI: 10.1177/1461444813487959.

van Deursen A and van Dijk J (2015) New Media and the Digital Divide. International Encyclopedia of the Social \& Behavioral Sciences. Second Edi. Elsevier. DOI: 10.1016/B978-0-08-097086-8.95086-4.

van Dijk J (2005) The Deepening Divide: Inequality in the Information Society. London: Sage.

van Dijk J (2006) Digital divide research, achievements and shortcomings. Poetics 34: 221235. DOI: 10.1016/j.poetic.2006.05.004.

Wallis C (2011) New Media Practices in China: Youth Patterns, Processes, and Politics. International Journal of Communication 5: 406-436. DOI: 1932-8036/20110406.

Warschauer M (2003) Technology and Social Inclusion: Rethinking the Digital Divide. London: MIT Press.

Warschauer M (2011) Learning in the Cloud: How (and Why) to Transform Schools with Digital Media. New York: Teachers College Press.

Whyte MK (2010) One Country, Two Societies: Rural-Urban Inequality in Contemporary China. Cambridge, Mass.: Harvard University Press.

Wilkin S, Davies H and Eynon R (2017) Addressing digital inequalities amongst young people: conflicting discourses and complex outcomes. Oxford Review of Education 43(3). Routledge: 332-347. DOI: 10.1080/03054985.2017.1305058.

Xiang B (2007) How far are the left-behind left behind? A preliminary study in rural China. Population, Space and Place 13(3): 179-191. DOI: 10.1002/psp.437.

Xiao Z (2013) 'You are too out!': a mixed methods approach to the study of 'digital divides' in three Chinese senior secondary schools. Durham University. Available at: http://etheses.dur.ac.uk/8456/.

Xiao Z, Kasim A and Higgins S (2016) Same difference? Understanding variation in the estimation of effect sizes from educational trials. International Journal of Educational Research 77: 1-14. DOI: 10.1016/j.ijer.2016.02.001. 

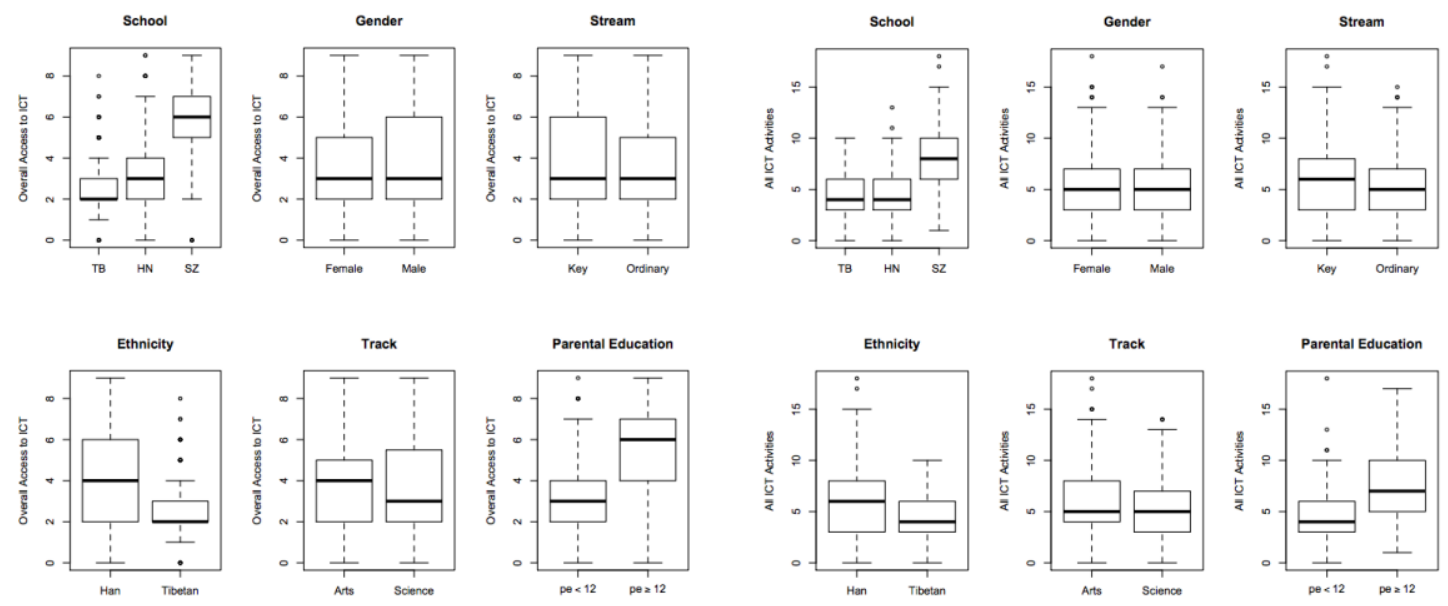

(a) Overall access to ICT by groups

(b) Total Internet activities by groups
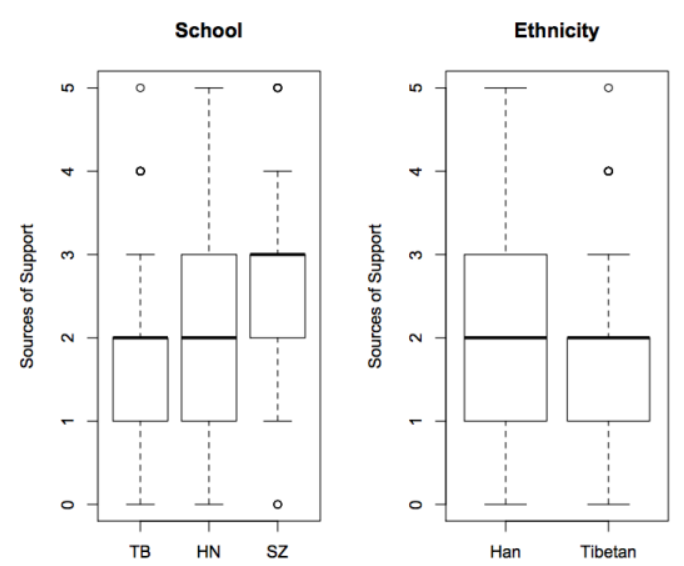

(c) Sources of support available
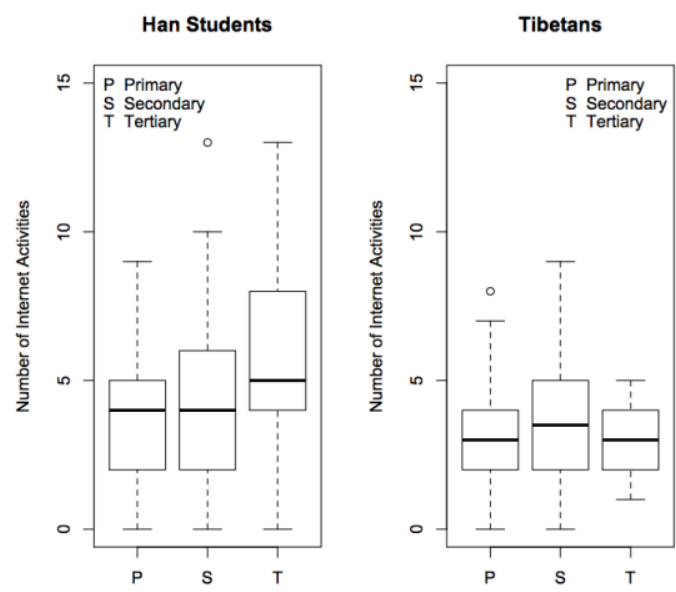

(d) Parental education and Internet activities

Figure 1: (a) Box plots comparing overall access to ICT by groups - TB, HN, SZ stand for Tibet, Hunan, and Shenzhen respectively, pe refers to parental education in years. (b) Comparing total number of Internet activities by groups. (c) Self-reported sources of support available when students encountered difficulties in their use of ICT. (d) Correlation between parental education and number of Internet activities. 


\begin{tabular}{l|cccc}
\hline & Estimate & Std. Error & $t$-Value & $\operatorname{Pr}(>|t|)$ \\
\hline Intercept (Being Han) & 2.20 & 0.37 & 5.99 & 0.00 \\
Parental Education & 0.22 & 0.03 & 6.70 & 0.00 \\
Being Tibetan & 0.99 & 0.50 & 1.97 & 0.05 \\
pe:ethTibetan & -0.19 & 0.06 & -3.08 & 0.00 \\
\hline
\end{tabular}

Table 1: Regression coefficients of the interactive model - pe:ethTibetan is the interaction between parental education and being Tibetan. 


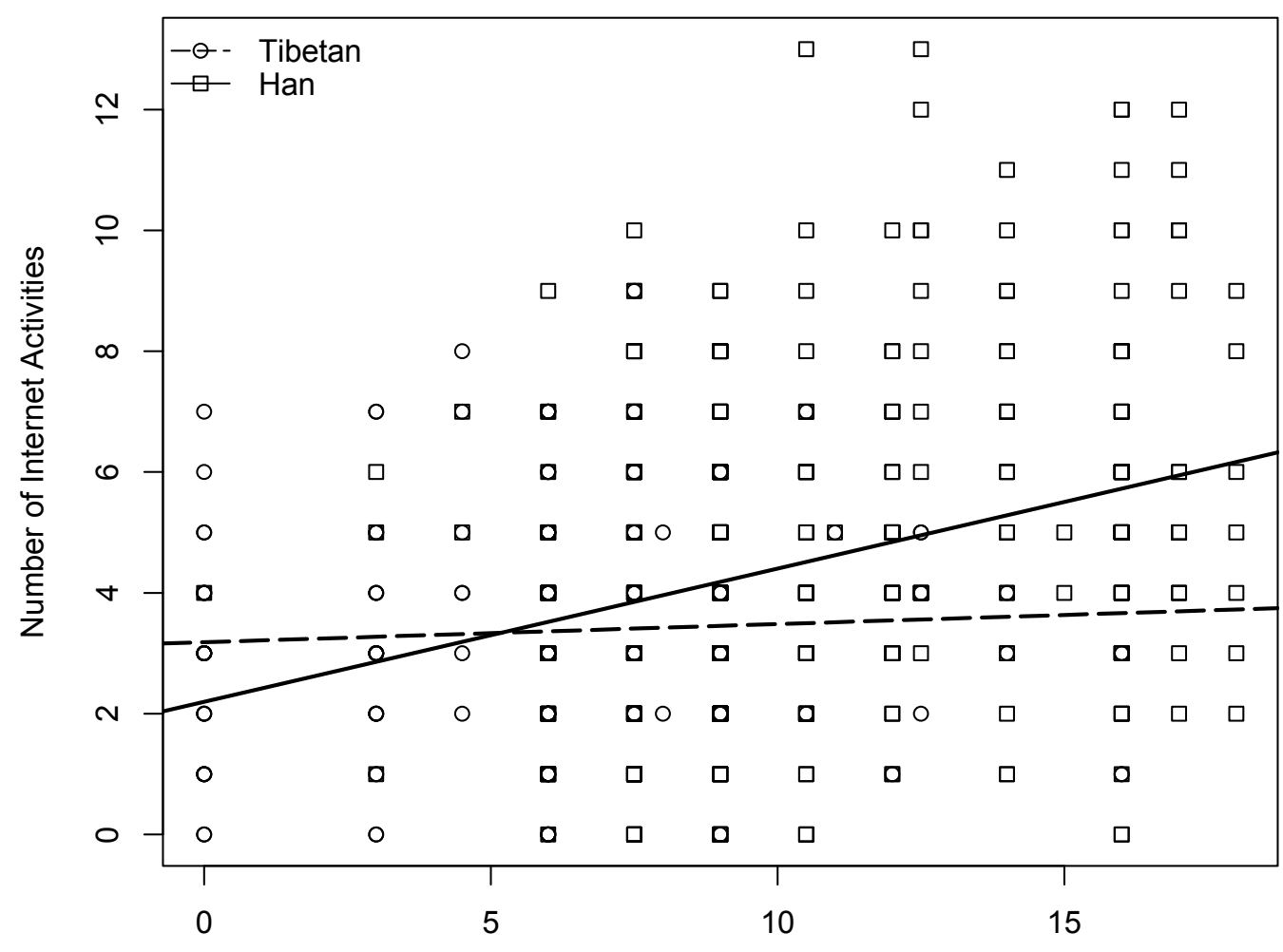

Parental Education in Years

Figure 2: Using parental education, ethnicity, and their interaction to predict self-reported number of Internet activities in an interactive linear model, which results in two intersecting regression lines, one for Han (solid) and the other (dashed) for Tibetan students. 


\begin{tabular}{l|ccc|ccc|ccc}
\hline & \multicolumn{3}{|c|}{ Mean Imputation } & \multicolumn{3}{c|}{ Reg. Imputation } & \multicolumn{3}{c}{ Amelia $(m=10)$} \\
& $\hat{\beta}$ & $s e$ & $p$ & $\hat{\beta}$ & $s e$ & $p$ & $\hat{\beta}$ & se & $p$ \\
\hline Intercept & 2.36 & .35 & .00 & 2.07 & .35 & .00 & 2.27 & .36 & .00 \\
Parental Education & .21 & .03 & .00 & .23 & .03 & .00 & .22 & .03 & .00 \\
Tibetan & .88 & .49 & .07 & 1.04 & .48 & .03 & .82 & .48 & .09 \\
pe:ethTibetan & -.21 & .06 & .00 & -.20 & .06 & .00 & -.18 & .06 & .00 \\
\hline
\end{tabular}

Table 2: Regression coefficients of the interactive model based on datasets imputed using different imputation methods, namely, mean, regression, and multiple imputation in Amelia. 